\title{
O ROMANTISMO DE NOVALIS \\ THE ROMANTICISM OF NOVALIS ${ }^{1}$
}

Adolphe BOSSERT

\section{APRESENTAÇÃO DA TRADUÇÃO}

Expressar-se sobre Novalis torna-se, de certo modo, algo outro. Quer dizer, ao falar ou dizer que seja poucas palavras em relação a este autor do romantismo alemão, é quase que evocar misticismo. Para tanto, seu nome envolve muita reflexão do ponto de vista cultural, tanto em sua época quanto em épocas póstumas. O século presente carece inexoravelmente de atenção especial, principalmente quando pensamos no modo como o homem vive cujo comportamento apresenta-se distante do seu ser, no sentido fenomenológico.

Assim sendo, em se tratando de Novalis, deve-se considerar o contexto histórico e geográfico em que viveu. Não obstante, Novalis encanta, embriaga, seduz e em certo sentido faz o leitor se deparar face a face com o seu ser (ontologicamente) cada vez mais estranho. Evocá-lo, assim como descrito no presente texto, mostra a importância deste autor na literatura mundial. Autor pouco conhecido e pouco estudado, Hardenberg (Novalis), o idealismo alemão e o romantismo formam, por assim dizer, um único mar da filosofia e da poesia da e na Alemanha do final do século XVIII e início do século XIX.

Novalis equivale o romantismo alemão; seu nome traduz o movimento vanguardista da Alemanha idealista. Muito se fala sobre Schelling, os irmãos Schlegel, Schiller, Goethe, Hegel, Fichte, Hölderlin entre outros, todos relacionados aos ideais alemães na transição de pensamentos sobre a forte influência da filosofia kantiana para a pós-kantiana. Porém, raros são aqueles que pronunciam o nome de Novalis. Poeticamente pode-se dizer - de forma audaciosa - que este pensador fez revolucionar ideias no qual a primeira metade do século XIX deixou-se marcar fixamente na história do desenvolvimento filosófico europeu.

Com seu estilo único, através de seus fragmentos e de seus textos em muitas ocasiões incompletos, Novalis traduziu o intraduzível, viu o invisível, disse o inaudito, tocou o intocado, pensou o impensado de forma simples e profunda. Isto tudo, no momento em que viveu. A pouca idade vivida mostra o quanto Novalis produziu magistralmente e genialmente, bem como ilustra o quanto poderia ter desenvolvido se sua vida não fosse interrompida precocemente.

\footnotetext{
${ }^{1}$ Traduzido por Marquesssuel Dantas de Souza. Geógrafo (USP). E-mail: marquessuelgf@ hotmail.com
} 


\section{Solilóquio a Novalis}

Um dos mais

Significativos representantes

Do romantismo alemão.

Novalis,

O Hardenberg da flor azul,

Do romantismo e do idealismo mágico,

O poeta e o filósofo que viu na poesia

A essência da natureza humana

E da existência.

Novalis,

Singular dentre muitos outros

Do idealismo e do romantismo alemão.

O romantismo idealista ou,

O idealismo romântico

Diz o nome "Novalis".

Um dos pensadores mais geniais,

Mais expressivos e notáveis

Do movimento que marcou época.

Novalis,

Seu nome equivale

O primeiro romantismo alemão.

$$
* * *
$$

Quando a noite é,

A mesma torna-se singular.

A noite é escura

Devido o excesso de luz,

\begin{tabular}{|c|c|c|c|c|}
\hline Qonista Dialectus & Ano 2 & n.7 & Setembro - Dezembro 2015 & p. $152-160$ \\
\hline
\end{tabular}


A mesma é clara e

Em virtude da demasiada

Escuridão que oculta

A luz noturna.

$\mathrm{O}$ amor perdido

Dói e muito profundamente.

Em fragmentos

Os versos são constituídos.

A juventude nos consome

De paixão pelo saber,

Pelo conhecimento.

A angústia amorosa

Invade-nos em demasia.

Novalis, que pensador...

No semblante da noite

Tudo se constitui,

Tudo se desfaz.

Pensamentos prudentes

Para além do habitual,

Flores perdidas

Do jardim secreto.

Conjugados sofrimentos

De ações perfeitas,

Sempre olhando o olho

Que não se vê.

Oh Narciso, onde estás?

\begin{tabular}{|l|l|l|l|l|}
\hline Qovista Dialectus & Ano 2 & n.7 & Setembro-Dezembro 2015 & p. $152-160$ \\
\hline
\end{tabular}


Morfeu... traz-me de volta...

Os deuses clamam

Junto a mim...

Quando é à noite,

A noite é de modo especial.

O presente texto constitui-se em uma breve resenha sobre Novalis, um dos mais importantes personagens do romantismo alemão. Poeta e filósofo, o presente manuscrito apresenta a relação entre e a vida e os escritos mais marcantes de Novalis. Faz uma sucinta análise da obra de poemas Hinos à Noite e do romance Heinrich von Ofterdingen; mostra a influência de Goethe, de Tieck e de Fichte sobre seu desenvolvimento como pensador. Do mesmo modo, ilustra brevemente a doutrina do idealismo mágico. Não obstante, ilustra o lugar de Novalis no romantismo.

\section{O ROMANTISMO DE NOVALIS ${ }^{2}$}

Georg Philipp Friedrich von Hardenberg, mais conhecido sob o pseudônimo de Novalis ${ }^{3}$, nasceu em 1772 em Ober-Wiederstedt, no condado de Mansfeld. Seu pai era diretor das salinas de Weissenfels (Weißenfels); ele mesmo fora destinado de boa hora à carreira das minas, no qual a princípio, simplesmente aceita e em que encontra mais tarde um lado poético. Após ter feito seus primeiros estudos no ginásio de Eisleben, se retira, em 1790, para a Universidade de Jena, onde conhece Fichte, os dois Schlegel e, sobretudo Schiller. Notamos desde então um traço peculiar de sua natureza que não fez se acentuar na sequência, uma carência de se prender e completamente de idealizar o objeto de sua ligação. Schiller, seu "prezado, grande Schiller", tronou-se o quanto antes, e imediatamente para ele, o tipo do

\footnotetext{
${ }^{2}$ Novalis. In: BOSSERT, A. Histoire de la Littérature Allemand. Paris: Hachette et $C^{\text {ie }}, 1901,1120$ p. Le Romantisme - Novalis, pp. 605-610. Tradução de Marquessuel Dantas de Souza. Estudante do Grupo de Pesquisa Geografia, Literatura e Arte (Geoliterart) da USP.

${ }^{3}$ Novalis é uma adaptação latina do nome de Hardenberg. Hard quer dizer floresta; Berg, montanha, rocha, mina; chamado novalis um terreno mineiro de recém exploração. Grifos do autor conforme o original. (Nota e grifos do autor).
}

\begin{tabular}{|l|l|l|l|l|}
\hline Q & Ano 2 & n.7 & Setembro-Dezembro 2015 & p. $152-160$ \\
\hline
\end{tabular}


gênio e da virtude, o homem ideal. Ele ${ }^{4}$ continua seu aprendizado em Leipzig e em Wittemberg, e entra na carreira ativa no ano de 1794, em Weissenfels. O ano seguinte (1795) marca uma data no desenvolvimento de seu espírito. Os primeiros livros de Wilhelm Meister ${ }^{5}$ aparecem; ele não se limita a os ler; os estuda e se empenha, e encontrou, segundo o hábito dos românticos, verdades profundas envolvidas de símbolos. No mesmo ano, ele conheceu aquela que foi "sua Clarisse". Era Sophie von Kühn, que o encanta sem dúvida por um conjunto de qualidades opostas as suas. É apresentado como um modelo de candura e espírito natural, sem nada de sentimental. Ela estava com apenas doze anos; era quase uma criança; entretanto Hardenberg se compromete com ela. Mas ela caiu doente quase imediatamente e morre dois anos após. Então ela a transfigura em sua imaginação, e foi, durante alguns anos, o centro ideal de sua vida. A morte de Sophie tronou-se, para ele, o ponto de partida de uma nova era, depois o qual ele a data, registra-a em seu jornal íntimo, seu diário, em suas memórias. Logo, invertendo os papeis, ele pensa que era ela que vivia, ao passo que ele mesmo permaneceu mergulhado na morte e que ela se foi antes dele para convidá-lo em seguida; e se pergunta se é a vontade do homem que transforma o mundo; não foi forte o suficiente para ultrapassar as portas da eternidade. "Eu quero morrer", disse-o um dia, "não como um ser esgotado que a natureza abandona, mas livre como o pássaro de passagem que procura outros climas, e feliz como um jovem poeta”. É com esses pensamentos que ele compõe os Hinos à Noite, que apareceu na Athenäeum de 1800. São escritos em prosa, mas numa prosa rítmica que se ler como versos. É a transcrição poética do diário íntimo. O estilo é simples e conciso. Novalis, que teve de ler as Noites de Young, conhecia os defeitos do gênero fúnebre, e hábil escritor que fora, soube os evitar. Reina em seus hinos uma espécie de alegria mística, que já é uma reação contra a dor. Sentimos que o poeta, no meio de seu luto, permanece jovem e que sua morte voluntária, deliberada, será seguida de uma imediata ressurreição.

Encontramo-lo, desde o fim do ano de 1797, em Freiberg, ocupado de mineralogia e geologia. Inteiramente ocupado em filosofar se guia em aparência, depois com Fichte, mas em realidade deixando-se levar por sua imaginação. Uma ideia, que já está expressa nos Hinos e nas passagens correspondentes de seu diário íntimo, e forma o fundo de sua filosofia: esta é o todo-poder de mim, cuja missão é subjulgar o mundo, não somente pelas conquistas lentas e progressivas da ciência, mas pelo poder imediato do espírito sobre a matéria, dizer a palavra,

\footnotetext{
${ }^{4}$ Referindo-se a Novalis. (N. T.).

${ }^{5}$ Referência à obra de Goethe. A partir de agora: Wilhem Meister, de Goethe. - Os grifos no corpo do texto são do autor conforme o original. Alguns grifos não especificados nas notas são do tradutor. (N. T.).

\begin{tabular}{|c|c|c|c|c|}
\hline Rovista Alatectus & Ano 2 & n.7 & Setembro - Dezembro 2015 & p. $152-160$ \\
\hline
\end{tabular}
}


pela magia. Novalis encontrou a última forma do idealismo de Fichte: é, para empregar sua própria expressão, o idealismo mágico. Ele previu o memento onde, ao lado da lógica, haveria uma arte mais elevada; é a arte de pensar e de criar pelo pensamento que ele chama $o$ fantástico: esta será a arte de criar por um ato instantâneo de mim, a arte de realizar nossos sonhos. Não é necessário perguntar para Novalis mais precisões semelhantes de ideias que comportam; é preciso deixar a alegria inocente e deleitar-se de visões e de quimeras.

Sua política é também inocente assim como sua filosofia; ela é a consequência de esperanças que toda a Prússia liberal se vê ligada ao advento de Frederico Guilherme III (Friedrich Wilhelm III). O novo rei é, o quanto antes, para ele, o soberano ideal; a rainha Louise ele a chama de a Nathalie de Wilhelm Meister, o mesmo ideal. Todos os dois são propostos a serem objetos como de perfeitos modelos; exemplo que lhes dão é melhor que uma constituição; sua vontade é a melhor das leis. É em sua vizinhança imediata e sob sua influência direta que devem se formar os altos funcionários do Estado. Mesmo a etiqueta do coração necessário; é uma escola de elegância e de bons costumes. A política de Novalis é uma política de contos de fadas. Devo dizer, por ser justo, que suas teorias são conhecidas por seus fragmentos, e eles teriam sem dúvida, retificados se ele tivesse que dar-lhes uma forma definitiva.

A poética de Novalis é a consequência de sua psicologia. Ela tem, no fim das contas, uma só ideia, ou antes, uma única necessidade moral que se exprime de diversas maneiras: é uma necessidade maravilhosa. Sua poética também resulta daí. Ele vê na alma disposições profundas, inomináveis, imperceptíveis, que não pertence a nenhuma faculdade, e que constituem nossa essência íntima. Estas são as disposições que a poesia deve despertar em nós. A poesia é uma língua interior, uma conversação da alma com ela mesma. Ela deve evitar encerrar-se nas formas excessivamente precisas: toda precisão, todo limite é deprimente e entrava o livre voo da alma. - A primeira das artes é a música, e a poesia tem, no entanto, mais potência do que ela ${ }^{6}$ de aproxime-se mais da música e do canto ${ }^{7}$. Como a poesia nos revela o segredo do nosso ser, ela mesma nos revela o sentido oculto da natureza, esta em que poderíamos chamar: sua alma. Ora, a alma da natureza ${ }^{8}$ é maravilhosa. Os fenômenos do

\footnotetext{
${ }^{6}$ Nesta passagem, o autor torna-se um pouco obscuro, mas ele se refere à música. Numa palavra, o autor diz que para Novalis a poesia é mais potente em relação à música. (N. T.).

${ }^{7}$ Novalis vai até dizer, em um de seus fragmentos: poderíamos conceber poesias que não fariam nenhum sentido e que não seriam feitas de palavras harmoniosas, crônicas que não teriam nenhuma ligação e cujas partes não estariam juntas, como os sonhos, por associações ideais. (Nota do autor).

${ }^{8}$ A este respeito, Os Discípulos em Saïs - de Novalis - é uma obra em que a ideia de natureza permeia toda a segunda parte do texto. Neste escrito Novalis discute sobre a Natureza; de certo modo, poder-se-ia dizer, ser uma conversação filosófico-literária, sobre o tema. Não obstante, deve-se notar que para Novalis a 'alma da natureza'

\begin{tabular}{|c|c|c|c|c|}
\hline Rovista Dialectus & Ano 2 & n.7 & Setembro - Dezembro 2015 & p. $152-160$ \\
\hline
\end{tabular}
}


mundo, para serem habituais, não são menos estranhos; o poeta rompe nossos hábitos de observação e nos faz ver a criação como se ela se oferecesse pela primeira vez a nossos olhos; ele nos surpreende, espanta-nos. O poeta é um encantador; é um perpétuo espetáculo esplêndido e maravilhoso que se abre diante nós.

O romance Heinrich von Ofterdingen é a aplicação destas teorias. É, sob forma alegórica, um tratado de educação do poeta; é ao mesmo tempo uma confissão do autor. Novalis tinha encontrado, em 1798, Sophie von Kühn na pessoa de Julie von Charpentier, filha de um engenheiro de minas, e tinha contraído um novo noivado. No ano seguinte, em uma viagem a Jena, ele conhece Tieck - e imediatamente -, inicia uma estreita amizade com ele. Os contos de Tieck e as Peregrinações Sternbald ${ }^{9}$ substituíram, em sua admiração, o Wilhelm Meister, o qual encontrou neste momento prosaico "uma história burguesa e doméstica, com comediantes musas”. Ele entra em um novo período de atividade, malgrado a doença que começa a minar e que só ele não percebeu o progresso. Heinrich von Ofterdingen seria a contrapartida de Wilhelm Meister, mas para uma poética romântica; mesmo formato, a impressão seria idêntica, de modo que não haveria nenhuma dúvida sobre a intenção do autor. Infelizmente, Novalis não viu a publicação de uma obra a qual ele fixou tão elevadas esperanças. Não pôde terminar a primeira parte e o resto dos curtos fragmentos da segunda; mas o sentido geral do romance é bastante claro, sobretudo se queremos aproveitar as indicações que nos dá Tieck, após as confissões que ele havia recebido do poeta. A primeira parte começa com um sonho e termina com um conto. Um e outro contêm, pressentindo o destino do herói. - Heinrich von Ofterdingen, o autor, o escritor presumido do Nibelungo, poeta nato ${ }^{10}$; cresce sob os olhos de seus familiares em Eisenach na Saxônia, meditando e sonhando, sem que nada venha contrariar a eclosão de seu gênio. Ele viu em sonho a flor $a z u l^{11}$, a meta ideal de sua vida. Mas, se quer cumprir sua missão, é preciso primeiro conhecer o mundo. Ele encaminha-se, com uma caravana de comerciante, a partir de seu avô em

trona-se sinônimo, assim compreende-se, de 'alma do mundo', uma referência, assim acredita-se, à obra de Schelling, Von der Weltseele, de 1798. - Nos Hinos à Noite, em algum momento surge a frase 'a alma do mundo': "l'anima del mondo" - die Seele der Welt (NOVALIS, 1984, p. 83). NOVALIS. Inni Alla notte - Canti spiritualli. (Traduzione de Roberto Fertonani a cura do Virginai Cisotti). $2^{\mathrm{a}}$ edizione. Con testo a fronte. Milano: Arnaldo Mondadori Editore, 1984. 172p. (Biblioteca colla economia di classici; 37). Por conseguinte, para Novalis "a Natureza não será Natureza se não tiver espírito" (NOVALIS, 1963, p. 369). NOVALIS. Les disciples à Saïs. (Traduction par Maurice Maeterlinck). In: ALEXANDRE, Maxime (Org.). Romantiques allemands I. Paris: Gallimard, 1963, 1648p. (Collection bibliothèque de la Pléiade; 168). (N. T.).

${ }^{9}$ Obra de Ludwig Tieck, publicada em 1798. (N. T.).

10 "Heinrich était un poete né" (NOVALIS, 1963, p. 451). NOVALIS. Heinrich von Ofterdingen. (Traduction par Y. Delétang-Tardif). In: ALEXANDRE, Maxime (Org.). Romantiques allemands I. Gallimard, 1963, 1648p. (Collection bibliothèque de la Pléiade; 168). (N. T.).

${ }^{11}$ A Flor Azul é o ideal procurado no romance Heinrich von Ofterdingen. (N. T.).

\begin{tabular}{|c|c|c|c|c|}
\hline Revista Dialectus & Ano 2 & n.7 & Setembro - Dezembro 2015 & p. $152-160$ \\
\hline
\end{tabular}


Augsbourg, e, ao longo do caminho, muitos quadros interessantes se desenrolam diante seus olhos. Em Augsbourg, ele encontra o poeta-mágico Klingsohr, que lhe dá sábios avisos sobre os limites da arte, sobre os perigos do entusiasmo, sobre a necessidade de se observar, de se conter, de se controlar sem cessar ${ }^{12}$. A filha de Klingsohr, Mathilde, lhe aparece como uma flor azul que ele sonhara, mas ela morre - como Sophie von Kühn -, e o jovem poeta retoma suas viagens. Após o romance, estava na Itália, na Grécia, no Oriente e regressa na presença de Klingsohr, em uma luta poética como a que teve lugar, de acordo com a legenda, no castelo Wartbourg. Heinrich von Ofterdingen ama uma segunda vez, como Novalis, e desta vez a flor azul se chama Cyane: é Julie von Charpentier. Quando a aprendizagem do poeta terminou, ele entra numa existência superior, onde tudo o que viu e provou se espiritualiza e se transfigura em um mundo do além, mas que ainda é deste mundo, um céu sobre a terra. Ele reencontra Mathilde e Cyane, as confunde em uma mesma figura ideal. Assim, o desenvolvimento do poeta acaba na vida mística e contemplativa. Tendo percorrido todo o círculo da existência terrestre, tendo recolhido em si as imagens de todas as coisas, ele tem que redobrar-se mais sobre si mesmo para "entrar em sua alma como entrou em sua pátria". "Tudo me traz de volta para mim mesmo"13, disse Novalis em um de seus fragmentos, e esta palavra pode estar próxima da conclusão de seu romance.

Novalis morreu em 25 de março de 1801, não tendo realizado seu vigésimo nono ano. Tinha publicado, além dos Hinos, alguns artigos na Athenäeum, como cânticos religiosos ${ }^{14}$, que são as mais puras efusões de seu misticismo. Estes são impulsos do coração, que não perturbam nenhum pensamento proposital dogmático e alguns deles são de uma forma concluída. Friedrich Schlegel disse de Novalis em uma carta: "Ele não admite que haja algo

\footnotetext{
12 "Ein echter, ganzer Dichter scheint da dem romantischen wohlgemeinte Warnungen zu ertheilen; wir glauben etwa Goethe reden zu hören, wenn Klingsohr dem jungen Heinrich einschärft, er müsse vor allem seinen Verstand, seinen natürlichen Trieb zu wissen wie alles sich begiebt und untereinander nach Gesetzen der Folge zusammenhängt, sorgfältig ausbilden” (Haym, Die romantische Schule, p. 374). (Nota do autor).

- "Todo verdadeiro poeta parece transmitir aos românticos avisos bem intencionados; pensamos que ouvimos falar de Goethe, quando Klingsohr inculca o jovem Heinrich, ele deve treinar com cuidado, especialmente a sua mente, para saber o seu instinto natural, como qualquer coisa querida e relacionada entre si de acordo com as leis de sucessão" (HAYM, Rudolf, A escola romântica: uma contribuição para a história dos espíritos alemães, $1^{\text {a }}$ edição de 1870). Transcrição por Marquessuel Dantas de Souza.

13 “Tout me ramène en moi-même" (NOVALIS, 1963, p. 350). - Este fragmento nostálgico encontra-se na obra Os Discípulos em Saïs. Op. Cit. (N. T.).

${ }^{14}$ Para Madame de Staël, os cantos religiosos de Novalis haviam adquirido comovedora celeridade na Alemanha após sua morte. - No original francês: “... lorsqu'il n'était déjà plus que les chants religieux qu'il a composés ont acquis en Allemagne une célébrité touchante” (STAËL, 1845, p. 566). - Na versão espanhola: “... só cuando ya no existia han adquirido conmovedora celebridade en Alemania lós cantos religiosos que há compuesto" (STAËL, 1947, p. 162). - STAËL, Madame de. Alemania. (Traducción de Manuel Granell). Buenos Aires/Mexico: Espala - Calpe Argentina, S. A. 1947. 176p. (Colección Austral). STAËL, Madame de. De L’Allemangne. Paris: Libraire de Firmin Didot Frères, 1845. 592p.
}

\begin{tabular}{|c|c|c|c|c|}
\hline Revista 2 ialectus & Ano 2 & n.7 & Setembro-Dezembro 2015 & p. $152-160$ \\
\hline
\end{tabular}


de ruim neste mundo, ele crer que tudo se prepara para uma nova idade do ouro: eu nunca vi tal serenidade na juventude. Ele mesmo disse em uma de suas poesias: A natureza me fez este dom de poder sempre erguer um olhar feliz para o céu". Estas palavras indicam a verdadeira natureza e no mesmo instante, o limite de seu gênio. A escola ${ }^{15}$ que o adotou - pobre de obrasprimas -, fez muito barulho entorno de seu nome. Era chamado o profeta do romantismo. Para justificar este título, deveria ter, ou melhor, ele havia anunciado alguma coisa no mundo. Ora, sua filosofia, sua política, mesmo sua estética, são sonhos de infância. Novalis é, em suma, um personagem amável, e por momentos, um escritor gracioso; mas é desconhecido, ignorado, menosprezado e é errado, até injusto colocá-lo no primeiro nível e tirá-lo em plena $\operatorname{luz}^{16}$. É preciso deixá-lo no meio-dia onde ele viveu e aonde o grande público nunca irá procurá-lo, mas onde de tempos em tempos alguns delicados gostam de conversar com ele ${ }^{17}$.

\footnotetext{
${ }^{15} \mathrm{O}$ autor se refere à escola romântica, cuja mesma se fez adotar o nome de Novalis como um dos principais representes do movimento romântico da Alemanha do final do século XVIII. - É digno de nota lembrar que a escola romântica tinha como principais líderes, editores os irmãos Schlegel, fundadores da revista Athenäeum, 1798-1800. (N. T.).

${ }^{16}$ Neste momento, o autor chama a atenção para ao fato de que Novalis fora um dos maiores gênios do romantismo, contudo, fora injusto seu diminuto tempo de vida para uma glória tão evidente. Em outros termos, Novalis fora posto em alto nível, mas a existência o suprimiu em plena luz. (N. T.).

${ }^{17}$ Edições das obras e correspondência. - Os escritos de Novalis foram publicados por Friedrich Schlegel e Tieck; 2 vol., Berlin, 1802; $5^{\text {a }}$ Ed. 1837; $3^{\circ}$ volume por tieck e Ed. von Bülow, Berlin, 1846. - Nova edição, 3 vol., Berlin, 1901. - Gedichte (Poesia), por W. Beyschlag, $3^{\text {a }}$ Ed., Leipzig, 1886. - Raich, Novalis Briefwechsel mit Fridrich und August Wilhelm, Charlotte und Caroline Schlegel (Correspondência com Friedrich e August Wilhelm, Charlotte e Caroline Schlegel), Mayence, 1880.

Consultar. - Friedrich von Hardenberg genannt Novalis, Eine Nachlese aus den Quellen des Familienarchivs (Friedrich von Hardenberg, chamado Novalis, suplemento das fontes do arquivo da família), Gotha, 1873. - W. Dilthey, Novalis (dans les Preussische Jahrbücher, XV), (Novalis - nos Anuários da Prússia), Berlin, 1865. - E. Heilborn, Novalis der Romantiker (Novalis, o romântico), Berlin, 1901. (Notas e grifos do autor). - Transcrições por Marquesssuel Dantas de Souza.
}

\begin{tabular}{|c|c|c|c|c|}
\hline Qovista Dialectus & Ano 2 & n.7 & Setembro - Dezembro 2015 & p. $152-160$ \\
\hline
\end{tabular}

